\title{
Evaluation of cytochrome P450 3A4-mediated drug-drug interaction potential between P2Y12 inhibitors and statins
}

\author{
BO ZHANG ${ }^{1,2}$, GE ZHAN $^{1}$, QING FANG $^{1}$, FANG WANG ${ }^{1}$, YANG LI ${ }^{1}$, \\ YUHAO ZHANG ${ }^{1}$, LEI ZHAO ${ }^{1}$, GUOCUI ZHANG ${ }^{1}$ and BAOXIN LI ${ }^{1}$

\begin{abstract}
${ }^{1}$ Department of Pharmacology, College of Pharmacy, Harbin Medical University, Harbin, Heilongjiang 150081;
${ }^{2}$ Pharmacy Department, The Second Affiliated Hospital of Harbin Medical University (Institute of Clinical Pharmacy,
\end{abstract} \\ The Heilongjiang Key Laboratory of Drug Research, Harbin Medical University), Harbin, Heilongjiang 150086, P.R. China
}

Received August 15, 2018; Accepted March 6, 2019

DOI: $10.3892 / \mathrm{mmr} .2019 .10692$

\begin{abstract}
Ticagrelor and prasugrel are widely used in the treatment of acute coronary syndrome. The co-administration of ticagrelor or prasugrel with statins in the clinic has already drawn a great deal of attention. The aims of the present study were to evaluate the safety and effectiveness, and guide the rational clinical use of, co-administration of ticagrelor or prasugrel with statins by exploring potential drug interactions. The activity of cytochrome P450 family 3 subfamily A member 4 (CYP3A4) was detected, and its protein and mRNA expression levels were measured in a rat model and liver microsomes to evaluate the effect of the drug combinations on CYP3A4. High performance liquid chromatography, western blotting and reverse transcription-quantitative PCR were used to perform these investigations. The in vitro experiments suggested that ticagrelor inhibited CYP3A4 activity, with $\mathrm{IC}_{50}$ and inhibitor constant $\left(\mathrm{K}_{\mathrm{i}}\right)$ values of 68.74 and $26.47 \mu \mathrm{M}$, respectively; prasugrel also inhibited CYP3A4, activity with $\mathrm{IC}_{50}$ and $\mathrm{K}_{\mathrm{i}}$ values of 16.24 and $10.84 \mu \mathrm{M}$, respectively. When different dosages of the antagonists were combined with simvastatin or atorvastatin, the metabolic rate was reduced more effectively at higher dosages when compared with lower dosages. An in vivo pharmacokinetic study demonstrated that the co-administration of ticagrelor or prasugrel with simvastatin caused an increase in the principal pharmacokinetic parameters of the probe drug dapsone [area under the concentration/time curve (AUC) $)_{0-t}, \mathrm{AUC}_{0-\infty}$ and $\left.\mathrm{t}_{1 / 2}\right]$ and a decrease in clearance compared with ticagrelor, prasugrel or simvastatin alone. Additional studies confirmed that the two investigated P2Y12 inhibitors were able to decrease the protein level of CYP3A4 by promoting protein degradation through the
\end{abstract}

Correspondence to: Professor Baoxin Li, Department of Pharmacology, College of Pharmacy, Harbin Medical University, 157 Baojian Road, Harbin, Heilongjiang 150081, P.R. China E-mail: libx64@hotmail.com

Key words: ticagrelor, prasugrel, statins, cytochrome P450 family 3 subfamily A member 4, pharmacokinetics, drug-drug interactions proteasomal pathway, and combination with statins such as simvastatin had a synergistic inhibitory effect on CYP3A4 activity. These results demonstrated that the co-administration of P2Y12 inhibitors with simvastatin could markedly inhibit the activity of CYP3A4, and these findings will further influence the assessment of the clinical effectiveness (reduced or enhanced efficacy) and safety (bleeding and rhabdomyolysis) in the clinic.

\section{Introduction}

Cytochrome P450 (CYP450) enzymes are considered to be principal phase I drug-metabolizing enzymes involved in the biotransformation of $\sim 90 \%$ of pharmaceutical drugs $(1,2)$. The major CYPs include CYP1A, CYP2B, CYP2C, CYP2D, CYP2E and CYP3A (3). Previous studies have confirmed that cytochrome P450 family 3 subfamily A member 4 (CYP3A4) is abundantly expressed in the liver $(4,5)$ and participates in the metabolic reactions of $>50 \%$ of currently prescribed drugs (6). Recently, drug combination therapies have been the focus of an increasing amount of public interest. A previous study hypothesized that if co-administered drugs were substrates of the same CYP isozyme, then the inhibition or induction of CYP activity would lead to a variation in the plasma concentration of each drug and subsequently result in increased toxicity or decreased drug efficacy (7).

Cardiovascular diseases are the primary cause of mortality both in developed and developing countries, and are responsible for $31 \%$ of global mortalities (8). Among them, acute coronary syndrome (ACS) is a potentially fatal coronary artery disease that encompasses unstable angina, ST-segment elevation myocardial infarction (STEMI) and non-STEMI (9). The activation of platelets and secondary blood coagulation factors has been thought to be a key factor in the pathogenesis of ACS. Therefore, administering anti-platelet agents, lowering lipid levels and stabilizing arterial plaques are the primary methods of treating ACS. The latest American Heart Association/American College of Cardiology guidelines advocate P2Y12 inhibitors [clopidogrel, ticagrelor and prasugrel] as the standard anti-platelet therapy for patients with ACS (10). Ticagrelor and prasugrel are orally administered antagonists of the adenosine diphosphate P2Y12 receptor, which 
were listed and recommended in the European Society of Cardiology Guidelines for ACS Prevention in 2011 and 2012, respectively $(11,12)$. While ticagrelor and prasugrel produce an increased risk of bleeding, they may reduce the incidence of myocardial infarction and mortality from vascular disease or stent thrombosis $(13,14)$, when compared with clopidogrel, in patients with ACS. In addition, as statins exert an irreplaceable role in the treatment of coronary disease, as they are anti-inflammatory, stabilize plaque formation and improve endothelial function, they are usually combined with P2Y12 inhibitors in the treatment of ACS (15). Ticagrelor is a known substrate of CYP3A4 (16), whereas prasugrel is a pro-drug that is metabolized to its active metabolite by CYP3A4 (17). Although the combination of ticagrelor or prasugrel with statins benefits patients with ACS, this combination may be accompanied by the risk of metabolic drug-drug interactions (DDIs), which will have a substantial effect on the clinical efficacy and safety of the drugs.

Therefore, the present study investigated the effects of ticagrelor and prasugrel alone or in combination with statins on CYP3A4 activity in vitro and in vivo to evaluate their effectiveness and safety.

\section{Materials and methods}

Chemicals and reagents. Prasugrel (cat. no. 150322-73-9) was purchased from Shanghai Yuanmu Biotechnology Co. Ltd. Ticagrelor (cat. no. 274683-27-5) was purchased from Toronto Research Chemicals, Inc. Simvastatin (cat. no. 79902-63-9), atorvastatin (cat. no. 134523-03-8) and 6 $\beta$-hydroxy testosterone (cat. no. 62-99-7) were purchased from Sigma-Aldrich; Merck KGaA. NADPH (cat. no. 42934-87-2) was purchased from Roche Diagnostics. Testosterone (cat. no. 58-22-0) was purchased from Shanghai Yuanye Biotechnology Co. Ltd. Cortisone acetate (cat. no. 50-04-4) and dapsone (cat. no. 80-08-0) were purchased from the National Institutes for the Control of Pharmaceutical and Biological Products. The concentrations of prasugrel and ticagrelor in the present study were based on the clinical doses $(18,19)$ and $\mathrm{IC}_{50}$ values. The ReverTra Ace ${ }^{\circledR}$ quantitative PCR (qPCR) reverse transcription (RT) kit and SYBR Green Real-Time PCR Master Mix were purchased from Toyobo Life Science. The primers for CYP3A4 and GADPH were synthesized by Invitrogen; Thermo Fisher Scientific, Inc. The CYP3A4 antibody was provided by Santa Cruz Biotechnology, Inc. Goat anti-mouse secondary antibodies were purchased from LI-COR Biosciences. Acetonitrile (cat. no. 75-05-8) and methanol (cat. no. 67-56-1; Dikma Technologies, Inc.) used were of high performance liquid chromatography (HPLC) grade.

Animals and cell culture. A total of 76 male Sprague-Dawley rats aged 6-8 weeks $(200 \pm 20 \mathrm{~g})$ were purchased from the Animal Center of Harbin Medical University (Harbin, China). Rats were kept in a temperature-controlled $\left(23 \pm 2^{\circ} \mathrm{C}\right)$ and humidity-controlled $(50 \pm 10 \%)$ room with a 12:12 h light/dark cycle, and had free access to food and water. The animal experiments were performed in accordance with the guidelines of the ethics committee of College of Pharmacy, Harbin Medical University. The relevant license number was no. IRB2017018. HepG2 liver cancer cells were purchased from The Third
Affiliated Hospital of Harbin Medical University and cultured at $37^{\circ} \mathrm{C}$ in a humidified atmosphere of $5 \% \mathrm{CO}_{2}$ in DMEM with high glucose (HyClone; GE Healthcare Life Sciences) containing 10\% FBS (Gibco; Thermo Fisher Scientific, Inc.) and $1 \%$ penicillin-streptomycin solution. Cells were examined by MTT assay to determine the effect of ticagrelor and prasugrel on their growth and activity. DMSO was used to dissolve the formazan crystals and absorption was measured at $490 \mathrm{~nm}$.

Preparation of rat liver microsomes. Rat liver microsomes were prepared as follows. Rats were euthanized by cervical dislocation after an intraperitoneal injection of pentobarbital sodium $(30 \mathrm{mg} / \mathrm{kg})$, and their livers were rapidly excised. The liver was subsequently washed with an ice-cold $0.9 \% \mathrm{NaCl}$ solution, weighed, minced in $1 \mathrm{~g}: 4 \mathrm{ml}$ of homogenization buffer (0.05 M Tris-HCl; pH 7.4) and then homogenized. The homogenate was centrifuged at $9,000 \mathrm{x} \mathrm{g}$ at $4^{\circ} \mathrm{C}$ for $20 \mathrm{~min}$, and the supernatant was collected. The supernatant was further subjected to ultracentrifugation at $100,000 \mathrm{x}$ g for $60 \mathrm{~min}$ at $4^{\circ} \mathrm{C}$. The supernatant was then discarded, and the pellet was resuspended in $25 \%$ sucrose and stored at $-80^{\circ} \mathrm{C}$ until analysis.

CYP3A4 activity assay in vitro. The effects of ticagrelor and prasugrel on CYP3A4 activity were assessed in vitro by using rat liver microsomes to quantify the formation of $6 \beta$-hydroxy-testosterone from testosterone. The incubation mixture consisted of $20 \mu \mathrm{l}$ of $1 \mathrm{mg} / \mathrm{ml}$ rat liver microsomes, $10 \mathrm{mM}$ magnesium chloride and $400 \mu \mathrm{M}$ testosterone mixed with $180 \mu \mathrm{l}$ of $100 \mathrm{mM}$ potassium phosphate buffer $\left(\mathrm{KH}_{2} \mathrm{PO}_{4}\right.$ and $\mathrm{K}_{2} \mathrm{HPO}_{4} ; \mathrm{pH}$ 7.4). The concentrations of ticagrelor and prasugrel used ranged between 1 and $150 \mu \mathrm{M}$ and between 1 and $50 \mu \mathrm{M}$, respectively. The concentrations of simvastatin and atorvastatin used were 2.5 and $1.5 \mu \mathrm{M}$, respectively. Following a 5-min preincubation step, the reaction was initiated by adding NADPH solution. Incubation steps were ceased after $30 \mathrm{~min}$ by adding ice-cold acetonitrile containing a cortisone acetate internal standard (final concentration $12.5 \mu \mathrm{M}$ ). The incubation mixtures were subsequently mixed and centrifuged for $15 \mathrm{~min}$ at $16,500 \mathrm{xg}$ at $4^{\circ} \mathrm{C}$. The supernatant $(20 \mu \mathrm{l})$ was analyzed by HPLC (Agilent 1260 infinity II chromatograph; Agilent Technologies, Inc.). The chromatographic column was Diamonsil C18 (4.6x200 mm; $5 \mu \mathrm{m}$; Dikma Technologies, Inc.). A mobile phase consisting of methanol: water $(65: 35, \mathrm{v} / \mathrm{v})$ was used. The flow rate was set at $1.0 \mathrm{ml} / \mathrm{min}$. The wavelength was set at $245 \mathrm{~nm}$. The column temperature was set at $25^{\circ} \mathrm{C}$. All microsomal incubations were conducted in quintuplicate.

Pharmacokinetic study ex vivo. To determine the effects of ticagrelor and prasugrel on CYP3A4 in rats, the following experiments were performed using the probe drugs. According to the medications administered to each group, the rats were divided into six groups, including a control group $(0.3 \%$ carboxymethyl cellulose sodium salt solution), ticagrelor group $(18 \mathrm{mg} / \mathrm{kg})$, simvastatin group (4 mg/kg), ticagrelor and simvastatin combination group ( $18 \mathrm{mg} / \mathrm{kg}+4 \mathrm{mg} / \mathrm{kg})$, prasugrel group $(6 \mathrm{mg} / \mathrm{kg})$, and prasugrel and simvastatin combination group $(6 \mathrm{mg} / \mathrm{kg}+4 \mathrm{mg} / \mathrm{kg})$, with each group containing six rats. Following intragastric administration of the different drugs for 7 days, the probe drug dapsone $(10 \mathrm{mg} / \mathrm{kg})$ was injected intraperitoneally. Blood samples $(300 \mu \mathrm{l})$ were collected from 
the tail vein into heparinized tubes at $0.083,0.25,0.5,1,1.5,2$, $4,6,8$ and $10 \mathrm{~h}$, and centrifuged at $1,000 \mathrm{xg}$ for $10 \mathrm{~min}$ at $4^{\circ} \mathrm{C}$. The supernatants were then collected, mixed with the internal standard chlorzoxazone and vortexed. The mixture was added to dichloromethane and then centrifuged at 1,500 $\mathrm{x} g$ for $5 \mathrm{~min}$. The organic phase was collected, transferred to new tubes and dried with nitrogen at $40^{\circ} \mathrm{C}$. The residues were re-dissolved in an acetonitrile-water (25:75) system and then centrifuged at $9,100 \mathrm{x} \mathrm{g}$ for $5 \mathrm{~min}$. Finally, the sample $(20 \mu \mathrm{l})$ was analyzed by HPLC (Agilent 1260 infinity II chromatograph; Agilent Technologies, Inc.). The chromatographic column was Diamonsil C18 (4.6x200 mm; $5 \mu \mathrm{m})$. A mobile phase consisting of acetonitrile: $1 \%$ phosphoric acid solution $(36: 64, \mathrm{v} / \mathrm{v})$ was used. The flow rate was set at $1.0 \mathrm{ml} / \mathrm{min}$, the wavelength was set at $293 \mathrm{~nm}$ and the column temperature was set at $25^{\circ} \mathrm{C}$. Finally, all rats were euthanized by cervical dislocation after intraperitoneal injection of pentobarbital sodium $(30 \mathrm{mg} / \mathrm{kg})$ when the 10th h blood sample had been collected.

Assessment of CYP3A4 protein expression in vitro. Following incubation with ticagrelor or prasugrel for $48 \mathrm{~h}$, cultured cells were collected to detect the protein level of CYP3A4. To study the degradation pathway of the CYP3A4 protein, cells were cultured with MG132 (1 $\mu \mathrm{M}$; Abcam) for $48 \mathrm{~h}$. RIPA buffer (Beyotime Institute of Biotechnology) supplemented with PMSF (100:1, v/v; Shanghai Shenneng Bocai Biotechnology Co., Ltd.) was used for protein extraction. Protein concentrations were determined using the bicinchoninic acid (BCA) method. The proteins $(100 \mu \mathrm{g})$ were separated by SDS-PAGE with a $10 \%(\mathrm{v} / \mathrm{v})$ resolving gel and then transferred to a nitrocellulose membrane (Pall Life Sciences). The membranes were blocked with $5 \%(\mathrm{w} / \mathrm{v})$ skim milk for $2 \mathrm{~h}$ at room temperature and incubated with primary antibodies against actin (1:1,000; cat. no. TA-09; ZSGB-BIO) and CYP3A4 (1:100; cat. no. GR3216447-3; Abcam) at $4^{\circ} \mathrm{C}$ overnight. Following washing three times in PBST, the membranes were incubated with goat anti-mouse IRDye $800 \mathrm{CW}(1: 10,000$; cat. no. 926-32210; LI-COR Biosciences) for $1 \mathrm{~h}$ in the dark at room temperature. Following another three washing steps in PBS with Tween-20, the membranes were analyzed using an Odyssey infrared fluorescent scanning system (LI-COR Biosciences). The data were analyzed using Image Studio Version 4.0 (LI-COR Biosciences).

Assessment of CYP3A4 protein expression in vivo. To evaluate the expression of CYP3A4 protein in vivo, the aforementioned groupings and treatments were applied. On day 8 , the rats were euthanized by cervical dislocation after intraperitoneal injection of pentobarbital sodium $(30 \mathrm{mg} / \mathrm{kg})$ in the absence of probe drugs, and the livers were rapidly excised. Livers were added to the appropriate lysis buffer (Shanghai Beinuo Bitechnology Co., Ltd.), homogenized, and sonicated. Samples were then centrifuged at $16,500 \times \mathrm{g}$ for $15 \mathrm{~min}$ at $4^{\circ} \mathrm{C}$ and the supernatant was collected. Protein concentration were measured using the BCA method. The remaining liver tissue was stored at $-80^{\circ} \mathrm{C}$ for further analysis, including RT-qPCR and western blotting.

Assessment of CYP3A4 mRNA expression in vitro and in vivo. The effect of ticagrelor and prasugrel on the mRNA expression of CYP3A4 was determined by RT-qPCR. Total RNA was extracted from liver cancer cells and rat liver tissues with TRIzol ${ }^{\circledR}$ reagent (Invitrogen; Thermo Fisher Scientific, Inc.), according to the manufacturer's protocol. The primers were designed based on the CYP3A4 sequence from the NCBI website (https://www.ncbi.nlm.nih.gov/). The primers used in the present study were as follows: CYP3A4, 5'-AAGTCGCCT CGAAGATACACA-3' (forward) and 5'-AAGGAGAGAACA CTGCTCGTG-3' (reverse), and GAPDH 5'-ATCATCCCTGC CTCTACTGG-3' (forward) and 5'-CTGCTTCACCACCTT CTTG-3' (reverse). The total RNA was reverse-transcribed into cDNA using the ReverTra Ace ${ }^{\circledR}$ qPCR RT kit at $37^{\circ} \mathrm{C}$ for $15 \mathrm{~min}$ and $95^{\circ} \mathrm{C}$ for $5 \mathrm{~min}$. RT-qPCR was performed with a 7500 Fast Real-Time PCR System (Applied Biosystems; Thermo Fisher Scientific, Inc.) using the SYBR Green Real-time PCR Master Mix, according to the manufacturer's protocol. The RT-qPCR reaction program was performed as follows: $95^{\circ} \mathrm{C}$ for $10 \mathrm{~min}$ followed by 40 cycles at $95^{\circ} \mathrm{C}$ for $15 \mathrm{sec}, 60^{\circ} \mathrm{C}$ for $30 \mathrm{sec}$, and $72^{\circ} \mathrm{C}$ for $30 \mathrm{sec}$. Data are presented as the relative gene quantity $(R Q)=2^{-\Delta \Delta C q}(20)$. All experiments were carried out in triplicate.

Statistical analysis. All data are expressed as the mean \pm SD. Statistical analysis was performed using SPSS 16.0 (SPSS, Inc.) software to evaluate statistical differences. One-way ANOVA was used to estimate the significance of differences between the experimental groups and control groups. Post hoc tests (Tukey's test) were used following one-way ANOVA. $\mathrm{P}<0.05$ was considered to indicate a statistically significant difference. The $\mathrm{IC}_{50}$ values (defined as the half-maximal inhibitory concentration) were calculated by regression analysis using GraphPad Prism 5.0 Software (GraphPad Software, Inc.). The inhibition mechanism was determined from a Lineweaver-Burk plot. The inhibitor constant $\left(\mathrm{K}_{\mathrm{i}}\right)$ values were determined using a secondary plot based on the slopes of the regression lines in the Lineweaver-Burk plot vs. inhibitor concentration.

\section{Results}

Inhibition of CYP3A4 activity by ticagrelor alone or co-administered with statins. To determine whether ticagrelor affects the activity of the CYP3A4 enzyme, experiments were performed by incubating rat liver microsomes with varying concentrations of ticagrelor, ranging between 1 and $150 \mu \mathrm{M}$. The inhibitory potency of ticagrelor was examined by measuring the $\mathrm{IC}_{50}$ and $\mathrm{K}_{\mathrm{i}}$ value. The drug combinations were divided into potent $\left(\mathrm{IC}_{50} \leq 10 \mu \mathrm{M}\right)$, moderate $\left(\mathrm{IC}_{50} 10-50 \mu \mathrm{M}\right)$ and weak $\left(\mathrm{IC}_{50} \geq 50 \mu \mathrm{M}\right) \mathrm{CYP}$ inhibitors. As illustrated in Fig. 1A-C, ticagrelor inhibited the metabolism of testosterone catalyzed by CYP3A4 with $\mathrm{IC}_{50}$ and $\mathrm{K}_{\mathrm{i}}$ values of 67.84 and $26.47 \mu \mathrm{M}$, respectively. Thus, ticagrelor was revealed to be a weaker inhibitor of CYP3A4. Simvastatin and atorvastatin are also metabolized by CYP3A4. Subsequently, the effects of ticagrelor in combination with the two statins on the rate of metabolism of a CYP3A4 substrate were detected and are presented in Fig. 1D and E. Both low and high concentrations of ticagrelor in combination with statins exhibited stronger inhibitory effects on the metabolism of testosterone when compared with ticagrelor alone $(\mathrm{P}<0.05 ; \mathrm{n}=5)$. The metabolic rates are summarized in Table I. 
A
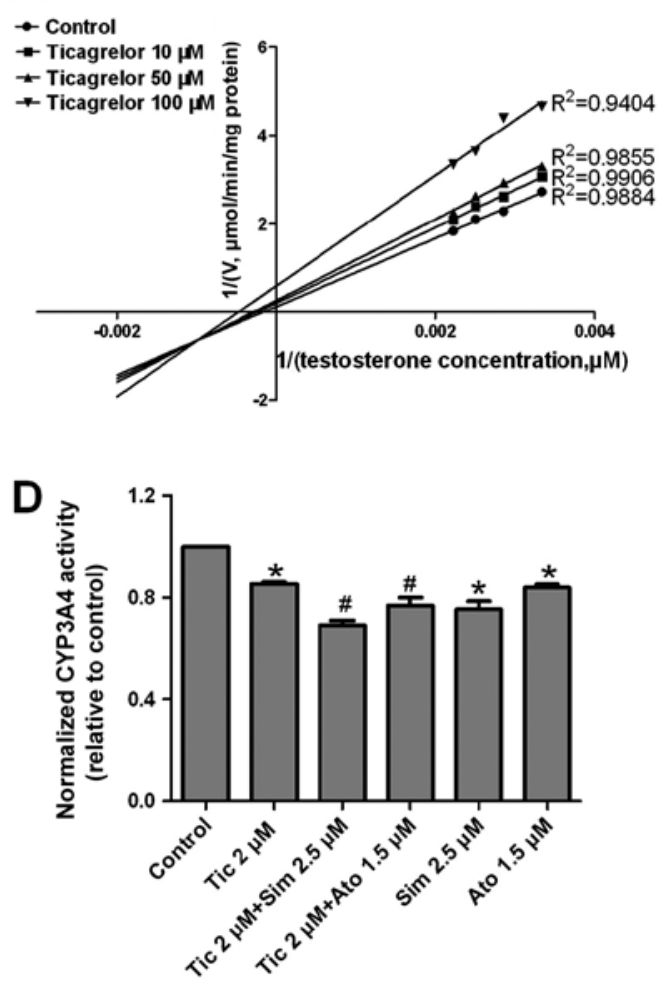

B

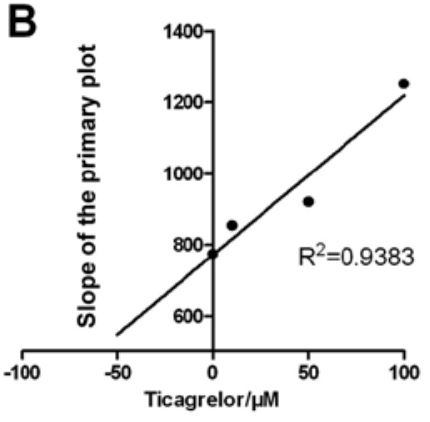

C

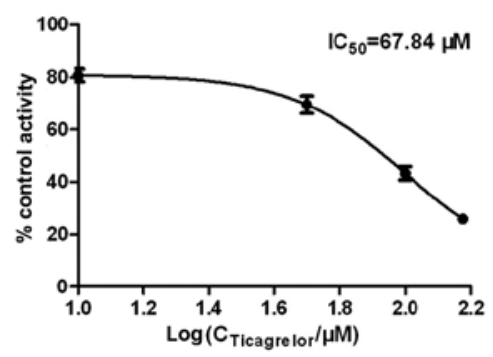

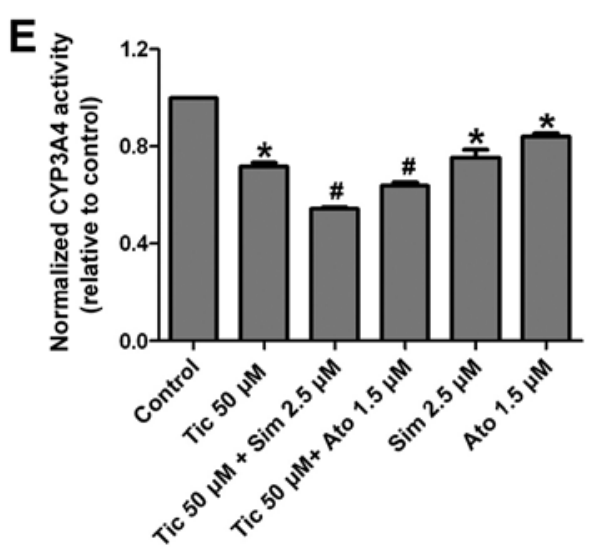

Figure 1. Effect of ticagrelor on the activity of CYP3A4 in rat liver microsomes, and the effect of co-administration of ticagrelor with statins on metabolic rate. (A) The primary Lineweaver-Burk plot for ticagrelor. (B) The secondary plot for determination of the $\mathrm{K}_{\mathrm{i}}$ of inhibition of CYP3A4-mediated probe substrate metabolism with 10,50 , and $100 \mu \mathrm{M}$ ticagrelor. (C) The $\mathrm{IC}_{50}$ curve for ticagrelor (10-150 $\left.\mu \mathrm{M}\right)$. (D) Combination with low-dose ticagrelor (2 $\mu \mathrm{M}$; $\mathrm{n}=5)$. (E) Combination with high-dose ticagrelor $(50 \mu \mathrm{M} ; \mathrm{n}=5)$. ${ }^{*} \mathrm{P}<0.05$ vs. control. ${ }^{\#} \mathrm{P}<0.05$ vs. respective ticagrelor alone group. CYP3A4, cytochrome $\mathrm{P} 450$ family 3 subfamily A member 4; Tic, ticagrelor; Sim, simvastatin; Ato, atorvastatin; $\mathrm{K}_{\mathrm{i}}$, inhibitor constant.

Inhibition of CYP3A4 activity by prasugrel alone or co-administration with statins. As illustrated in Fig. 2A-C, prasugrel inhibited CYP3A4 activity with $\mathrm{IC}_{50}$ and $\mathrm{K}_{\mathrm{i}}$ values of 16.24 and $10.84 \mu \mathrm{M}$, respectively. Thus, prasugrel was identified to be a moderate inhibitor of CYP3A4. In addition, the effects of prasugrel in combination with simvastatin or atorvastatin on CYP3A4 activity were evaluated. As presented in Fig. 2D and E, the combined application of prasugrel and statins significantly decreased testosterone metabolism compared with the application of prasugrel alone $(\mathrm{P}<0.05$; $\mathrm{n}=5$ ). The data are summarized in Table II.

Effects of ticagrelor or prasugrel on the protein expression and $m R N A$ levels of CYP3A4 in vitro. The results of the MTT assay (Data not shown) showed that ticagrelor $(2 \mu \mathrm{M})$ and prasugrel $(2 \mu \mathrm{M})$ had little effect on the growth and activity of liver cancer cells compared with the control group. In an attempt to elucidate the mechanism underlying the inhibitory effect of ticagrelor and prasugrel on CYP3A4 activity, the protein and mRNA expression levels of CYP3A4 were examined in liver cancer cells treated with ticagrelor $(2 \mu \mathrm{M})$ and prasugrel $(2 \mu \mathrm{M})$. As illustrated in Fig. 3A, CYP3A4 protein expression was downregulated by $16.58,36.97$ or $40.28 \%$ following treatment with ticagrelor alone, in combination with simvastatin or in combination with atorvastatin, respectively $(\mathrm{P}<0.05 ; \mathrm{n}=3)$. The results were consistent with the effects of the drug combinations on CYP3A4 activity in vitro. The mRNA expression of CYP3A4 was also determined. However, as Fig. 3B illustrates, the mRNA expression of CYP3A4 was significantly upregulated following treatment with ticagrelor alone or ticagrelor in combination with simvastatin or atorvastatin $(\mathrm{P}<0.05 ; \mathrm{n}=3)$. As presented in Fig. 3C and D, the protein expression of CYP3A4 was decreased and the mRNA expression of CYP3A4 was increased following treatment with prasugrel alone compared with the control $(\mathrm{P}<0.05 ; \mathrm{n}=3)$. Similar results were also obtained following treatment with prasugrel in combination with simvastatin or atorvastatin. Therefore, the degradation of CYP3A4 protein was detected due to the nonconformity between mRNA expression and protein expression results. To investigate the pathway of CYP3A4 degradation, MG132, a potent proteasome inhibitor, was used. As illustrated in Fig. 3E and F, the protein expression of CYP3A4 that was previously downregulated by treatment with ticagrelor or prasugrel was restored following exposure to MG132 $(\mathrm{P}<0.05 ; \mathrm{n}=3)$. These results suggested that the factor responsible for CYP3A4 degradation in response to ticagrelor and prasugrel may be the proteasome complex.

Effects of ticagrelor or prasugrel on the protein expression and $m R N A$ levels of CYP3A4 in vivo. The present study subsequently investigated the effects of ticagrelor or prasugrel on the protein expression and mRNA levels of CYP3A4 in vivo. The results presented in Fig. $4 \mathrm{~A}$ and $\mathrm{B}$ revealed that the protein expression of CYP3A4 was downregulated and that the mRNA expression was upregulated $(\mathrm{P}<0.05 ; \mathrm{n}=5)$. In addition, when 
Table I. Metabolic rates under treatment with ticagrelor, simvastatin, atorvastatin and co-administration.

Treatment group

\begin{tabular}{lccccc}
\cline { 2 - 6 } Measurement & Tic & Sim & Tic + Sim $(\%)$ & Ato & Tic + Ato (\%) \\
\hline $\mathrm{R}_{\mathrm{m}} / \mathrm{C}_{\mathrm{d}}$ & $85.36 \% / 2 \mu \mathrm{M}$ & $75.40 \% / 2.5 \mu \mathrm{M}$ & 69.99 & $83.91 \% / 1.5 \mu \mathrm{M}$ & 76.88 \\
$\mathrm{R}_{\mathrm{m}} / \mathrm{C}_{\mathrm{d}}$ & $71.82 \% / 50 \mu \mathrm{M}$ & $75.40 \% / 2.5 \mu \mathrm{M}$ & 54.18 & $83.91 \% / 1.5 \mu \mathrm{M}$ & 64.02 \\
\hline
\end{tabular}

$\mathrm{R}_{\mathrm{m}}$, metabolic rate; $\mathrm{C}_{\mathrm{d}}$, drug concentration; Tic, ticagrelor; Sim, simvastatin; Ato, atorvastatin.

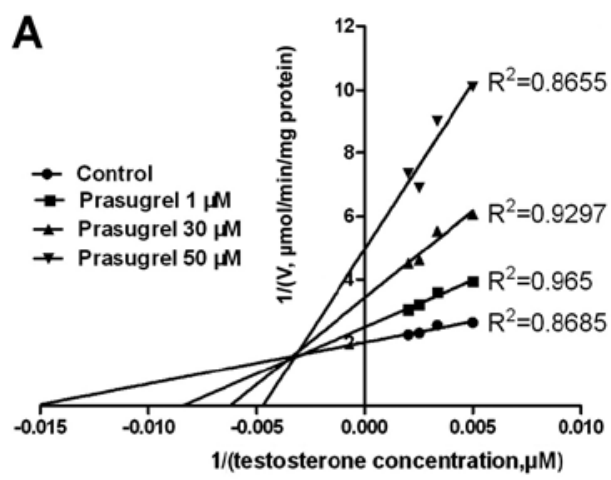

B

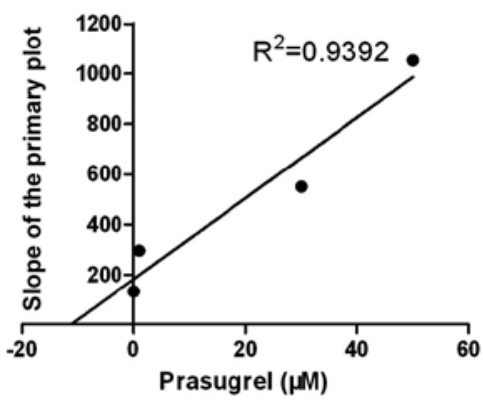

$\mathbf{E}$

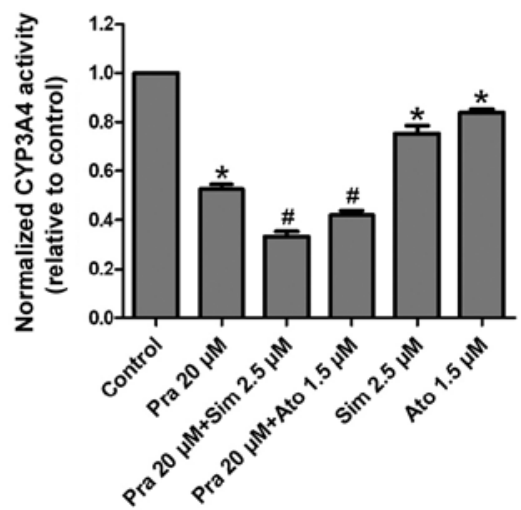

Figure 2. Effects of prasugrel on the activity of CYP3A4 in rat liver microsomes, and the effect of co-administration of prasugrel with statins on metabolic rate. (A) The primary Lineweaver-Burk plot for prasugrel. (B) The secondary plot for determination of the $\mathrm{K}_{\mathrm{i}}$ of inhibition of CYP3A4-mediated probe substrate metabolism with 1,30 and $50 \mu \mathrm{M}$ prasugrel. (C) The $\mathrm{IC}_{50}$ curve for prasugrel (1-50 $\mu \mathrm{M}$ ). (D) Combination with low-dose prasugrel (2 $\mu \mathrm{M}$; $\mathrm{n}=5$ ). (E) Combination with high-dose prasugrel $(20 \mu \mathrm{M} ; \mathrm{n}=5)$. ${ }^{*} \mathrm{P}<0.05$ vs. control. ${ }^{~} \mathrm{P}<0.05$ vs. respective prasugrel alone group. CYP3A4, cytochrome $\mathrm{P} 450$ family 3 subfamily A member 4; Pra, prasugrel; Sim, simvastatin; Ato, atorvastatin; $K_{i}$, inhibitor constant.

compared with the control group, the protein level of CYP3A4 was significantly decreased and the mRNA level of CYP3A4 was increased following treatment with prasugrel alone (Fig. 4C and D). The changes in protein expression and mRNA levels in vivo were consistent with those in vitro $(\mathrm{P}<0.05 ; \mathrm{n}=5)$.

Study on pharmacokinetic interactions of co-administration in vivo using a probe drug. The pharmacokinetic parameters of dapsone in the different groups (ticagrelor, prasugrel or co-administration with simvastatin) are summarized in Tables III and IV. The plasma concentration/time curves of dapsone are presented in Fig. 5. The data revealed that the area under concentration/time curve (AUC), half time $\left(t_{1 / 2}\right)$ and clearance (CL) of dapsone were altered following treatment with ticagrelor or prasugrel in combination with simvastatin compared with treatment with ticagrelor or prasugrel alone $(\mathrm{P}<0.05, \mathrm{n}=6)$. Compared with administration of ticagrelor alone, a slight change was identified in the of $t_{1 / 2}$ and CL values of dapsone following the administration of ticagrelor in combination with simvastatin. However, compared with administration of prasugrel alone, the $t_{1 / 2}$ of dapsone increased from $6.34 \pm 1.13$ to $17.53 \pm 6.11 \mathrm{~h}$, while the CL decreased from $0.27 \pm 0.04$ to $0.08 \pm 0.02 \mathrm{l} / \mathrm{h} / \mathrm{kg}$ following the administration of prasugrel in combination with simvastatin.

\section{Discussion}

Ticagrelor and prasugrel, the new generation of P2Y12 inhibitors, have taken the place of clopidogrel in the treatment of 
Table II. Metabolic rates under treatment with prasugrel, simvastatin, atorvastatin and co-administration.

Treatment group

\begin{tabular}{lccccc}
\cline { 2 - 6 } Measurement & Pra & Sim & Ato & Pra + Sim (\%) & Pra + Ato (\%) \\
\hline $\mathrm{R}_{\mathrm{m}} / \mathrm{C}_{\mathrm{d}}$ & $90.00 \% / 2 \mu \mathrm{M}$ & $75.40 \% / 2.5 \mu \mathrm{M}$ & $83.91 \% / 1.5 \mu \mathrm{M}$ & 62.99 & 70.15 \\
$\mathrm{R}_{\mathrm{m}} / \mathrm{C}_{\mathrm{d}}$ & $52.48 \% / 20 \mu \mathrm{M}$ & $75.40 \% / 2.5 \mu \mathrm{M}$ & $83.91 \% / 1.5 \mu \mathrm{M}$ & 33.33 & 42.00 \\
\hline
\end{tabular}

$\mathrm{R}_{\mathrm{m}}$, metabolic rate; $\mathrm{C}_{\mathrm{d}}$, drug concentration; Pra, prasugrel; Sim, simvastatin; Ato, atorvastatin.

A

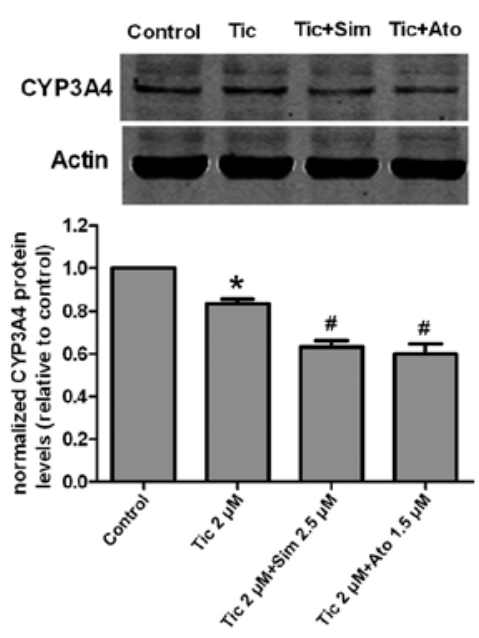

D

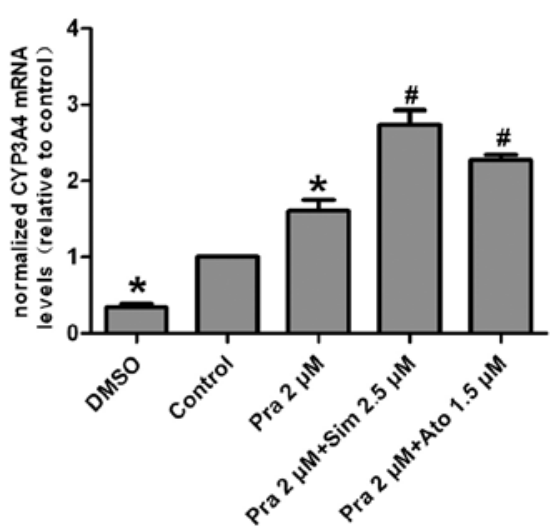

B

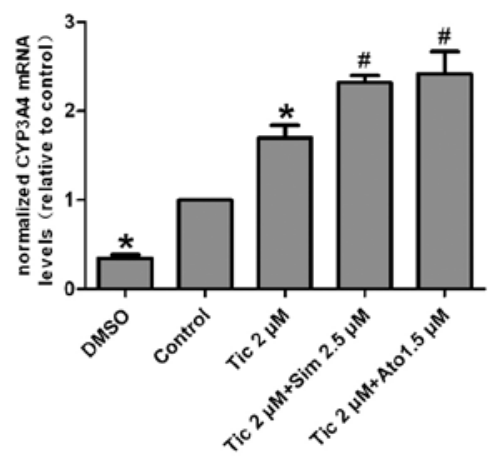

E
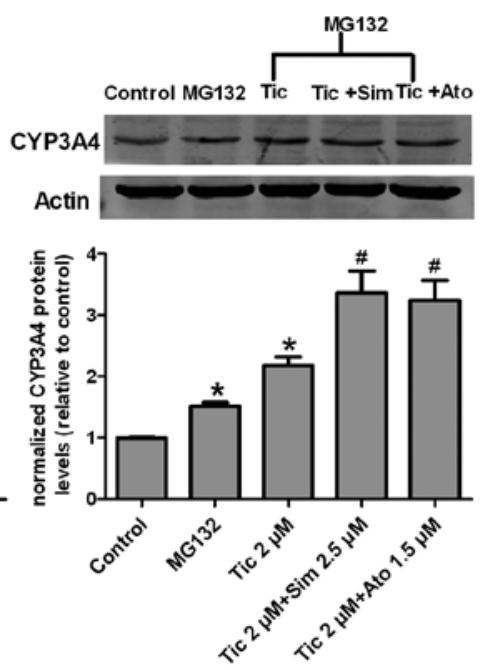

C
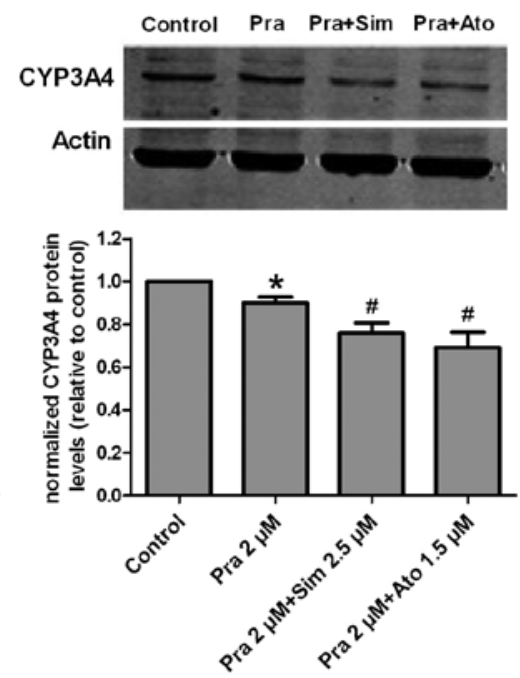

F

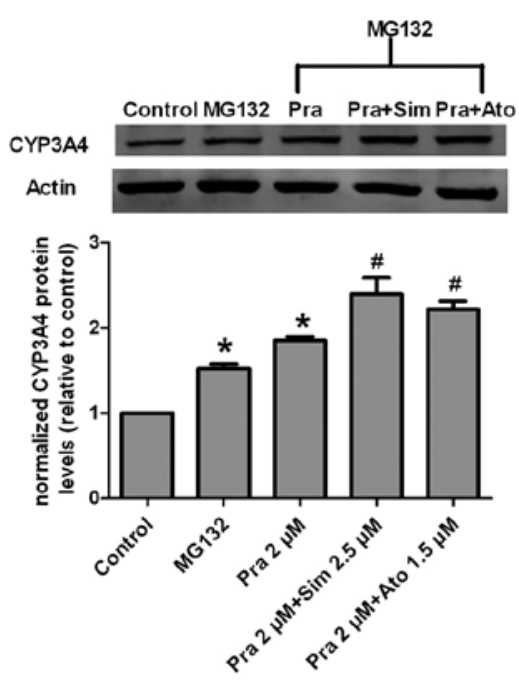

Figure 3. Effects of ticagrelor and prasugrel on the protein expression and mRNA levels of CYP3A4 in vitro. (A) Representative western blotting bands for samples from cells treated with different drugs demonstrating the effects on the expression of CYP3A4 protein, and the corresponding quantification and summary data (n=3). (B) Effects of drug exposure on the expression of CYP3A4 mRNA ( $n=3)$. (C) Representative western blotting bands for samples from cells treated with different drugs, showing the effect on the expression of CYP3A4 protein, and the corresponding quantification and summary data ( $\mathrm{n}=3$ ). (D) Effects of drug exposure on the expression of CYP3A4 mRNA (n=3). (E and F) Representative western blotting bands for samples from cells treated with different drugs and MG132 $(1 \mu \mathrm{M})$, showing the effects on degradation of CYP3A4 protein, and the corresponding quantification and summary data $(\mathrm{n}=3) .{ }^{*} \mathrm{P}<0.05$ vs. control. ${ }^{\text {"P }}<0.05$ vs. respective single drug group (Tic or Pra). CYP3A4, cytochrome P450 family 3 subfamily A member 4; Tic, ticagrelor; Sim, simvastatin; Ato, atorvastatin; Pra, prasugrel.

patients with acute coronary syndrome (ACS). Ticagrelor is an active drug, whereas prasugrel is a prodrug $(11,12)$. Combination therapy is widely used in the treatment of ACS and otherdiseases due to its advantages, such as improving therapeutic effects 
A
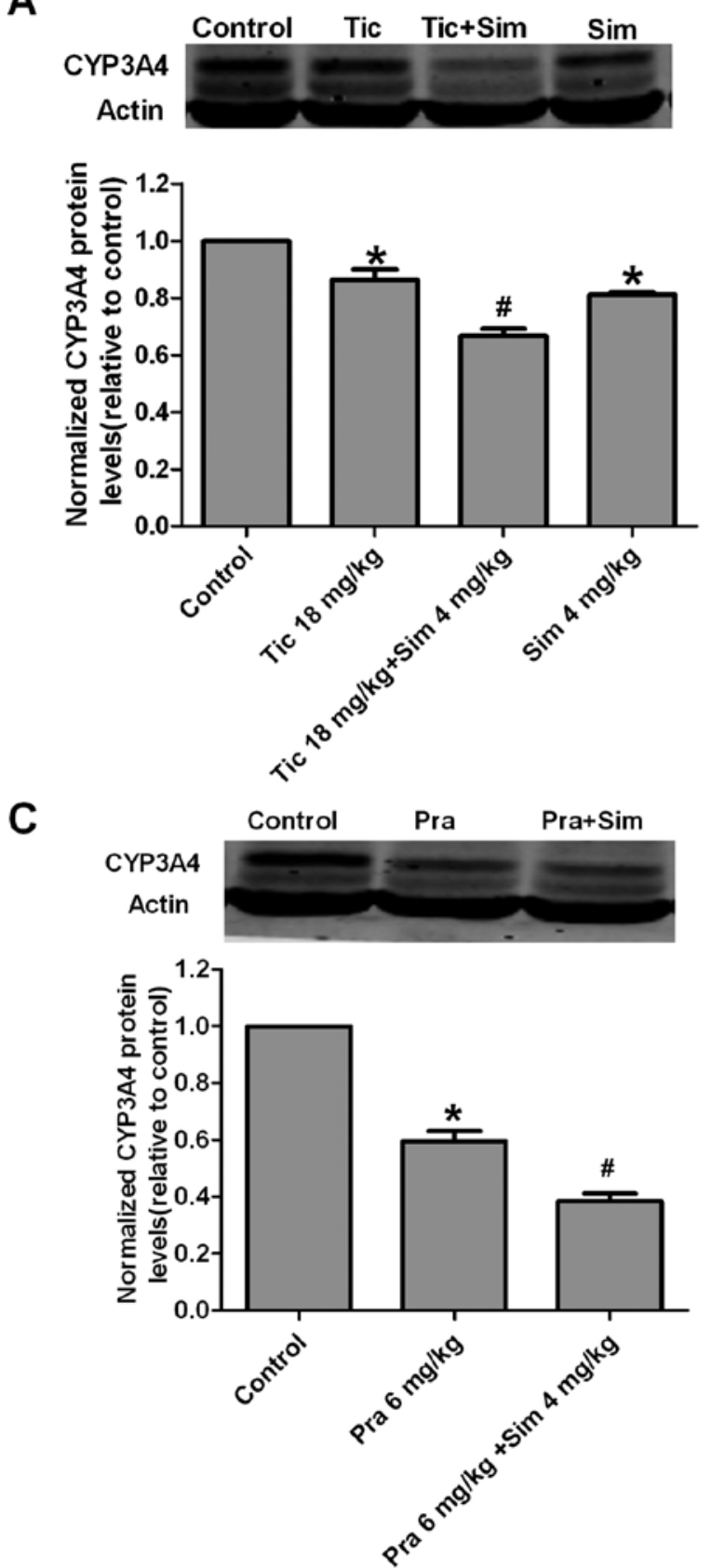

B

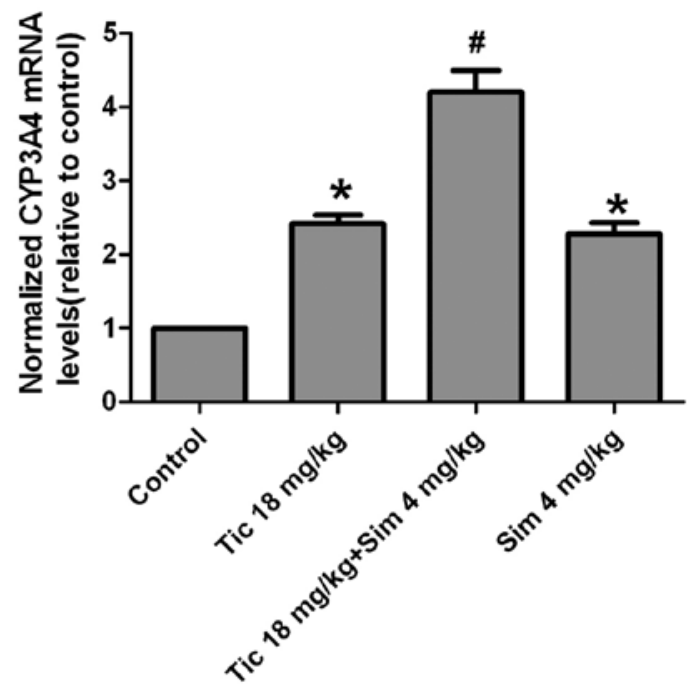

D

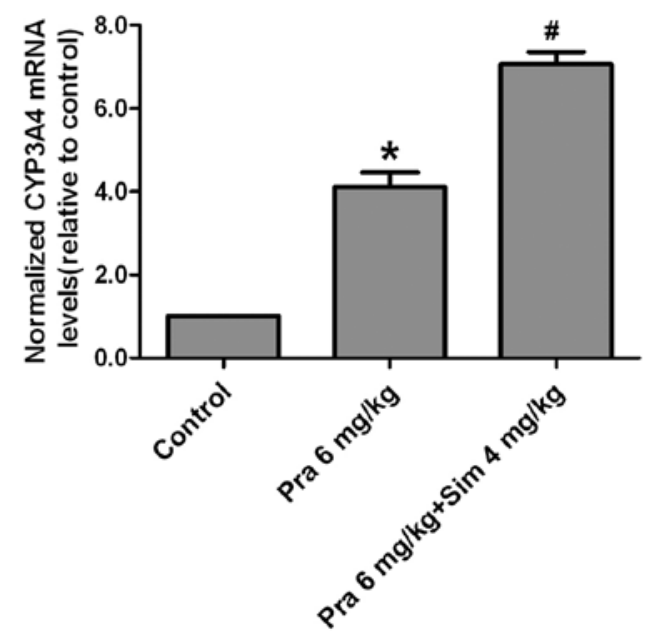

Figure 4. Effects of ticagrelor and prasugrel on the protein expression and mRNA levels of CYP3A4 in vivo. (A) Representative western blotting bands for samples from rat livers treated with ticagrelor, showing the effect on expression of CYP3A4 protein, and the corresponding quantification and summary data $(n=5)$. (B) Effects of ticagrelor on the expression of CYP3A4 mRNA ( $n=5)$. (C) Representative western blotting bands for samples from rat livers treated with prasugrel, showing the effect on the expression of CYP3A4 protein, and the corresponding quantification and summary data ( $\mathrm{n}=5$ ). (D) Effects of prasugrel exposure on the expression of CYP3A4 mRNA ( $n=5$ ). ${ }^{~} \mathrm{P}<0.05$ vs. control. ${ }^{~} \mathrm{P}<0.05$ vs. single drug group (Tic or Pra). CYP3A4, cytochrome P450 family 3 subfamily A member 4; Pra, prasugrel; Sim, simvastatin; Ato, atorvastatin; Tic, ticagrelor.

and reducing adverse reactions $(21,22)$. At present, patients with cardiovascular diseases are likely to take an anti-platelet agent concomitantly with a statin $(23,24)$. CYP3A4, which is one of the most important drug-metabolizing P450 isoforms, plays an important role in the biotransformation of many clinical drugs $(25,26)$. Previous studies have demonstrated that ticagrelor and prasugrel are metabolized by CYP3A4 $(27,28)$. Statins (3-hydroxy-3-methylglutaryl coenzyme A reductase inhibitors), such as simvastatin and atorvastatin, are also metabolized by CYP3A4 (29-31). If the co-administered drugs are substrates of CYP3A4, DDIs may occur resulting from the inhibition or induction of the CYP3A4 enzyme. The aim of the present study was to evaluate DDIs between the P2Y12 inhibitors (ticagrelor and prasugrel) and statins in vitro and in vivo. The results of the present study suggested that ticagrelor had a weak inhibitory effect on CYP3A4. The $\mathrm{IC}_{50}$ and $\mathrm{Ki}$ values were 67.84 and $26.47 \mu \mathrm{M}$, respectively. However, prasugrel had a moderate inhibitory effect on CYP3A4, with $\mathrm{IC}_{50}$ and $\mathrm{K}_{\mathrm{i}}$ values of 16.24 and $10.84 \mu \mathrm{M}$, respectively. The co-administration of ticagrelor or prasugrel with statins showed more potent inhibitory effects. Ticagrelor is an active drug that can be used in combination with statins to inhibit CYP3A4 
Table III. Main pharmacokinetic parameters of dapsone following a single use of ticagrelor, co-administration with simvastatin and simvastatin alone.

\begin{tabular}{lcccc}
\hline Parameters & Ctl & Tic & Tic + Sim & Sim \\
\hline $\mathrm{AUC}_{0-\mathrm{t}}, \mathrm{mg} / \mathrm{l} \cdot \mathrm{h}$ & $16.39 \pm 1.07$ & $21.80 \pm 1.02^{\mathrm{a}}$ & $30.08 \pm 1.50^{\mathrm{b}, \mathrm{c}}$ & $25.39 \pm 1.95^{\mathrm{a}}$ \\
$\mathrm{AUC}_{0-\infty}, \mathrm{mg} / \mathrm{l} \cdot \mathrm{h}$ & $18.12 \pm 1.17$ & $31.60 \pm 3.69^{\mathrm{a}}$ & $40.08 \pm 2.48^{\mathrm{b}, \mathrm{c}}$ & $30.56 \pm 3.69^{\mathrm{a}}$ \\
$\mathrm{t}_{1 / 2}, \mathrm{~h}$ & $3.01 \pm 0.60$ & $4.75 \pm 0.62^{\mathrm{a}}$ & $4.90 \pm 0.67^{\mathrm{a}, \mathrm{c}}$ & $3.82 \pm 0.92$ \\
$\mathrm{~T}_{\max }, \mathrm{h}$ & $0.46 \pm 0.29$ & $0.96 \pm 0.40$ & $1.25 \pm 0.27^{\mathrm{a}}$ & $1.17 \pm 0.26^{\mathrm{a}}$ \\
$\mathrm{CL}, \mathrm{l} / \mathrm{h} / \mathrm{kg}$ & $0.55 \pm 0.04$ & $0.32 \pm 0.04^{\mathrm{a}}$ & $0.26 \pm 0.02^{\mathrm{b}, \mathrm{c}}$ & $0.33 \pm 0.04^{\mathrm{a}}$ \\
$\mathrm{C}_{\max }, \mathrm{mg} / \mathrm{l}$ & $4.15 \pm 0.39$ & $4.15 \pm 0.83$ & $5.57 \pm 0.41^{\mathrm{b}}$ & $5.54 \pm 0.32^{\mathrm{a}}$ \\
\hline
\end{tabular}

${ }^{\mathrm{a}} \mathrm{P}<0.05$ vs. control. ${ }^{\mathrm{b}} \mathrm{P}<0.05$ vs. ticagrelor alone group $(\mathrm{n}=6) .{ }^{\mathrm{c}} \mathrm{P}<0.05$ vs. simvastatin alone group ( $\left.\mathrm{n}=6\right)$. Ctl, control; Tic, ticagrelor; Sim, simvastatin; AUC, area under the concentration/time curve; CL, clearance; $\mathrm{C}$, concentration; $\mathrm{T}$, time.

Table IV. Main pharmacokinetics parameters of dapsone following a single use of prasugrel, co-administration with simvastatin and simvastatin alone.

\begin{tabular}{lcccc}
\hline Parameters & Ctl & Pra & Pra + Sim & Sim \\
\hline $\mathrm{AUC}_{0-\mathrm{t}}, \mathrm{mg} / \mathrm{l} \cdot \mathrm{h}$ & $16.39 \pm 1.07$ & $24.97 \pm 2.81^{\mathrm{a}}$ & $42.16 \pm 4.17^{\mathrm{b}, \mathrm{c}}$ & $25.31 \pm 1.95^{\mathrm{a}}$ \\
$\mathrm{AUC}_{0-\infty}, \mathrm{mg} / \mathrm{l} \cdot \mathrm{h}$ & $18.12 \pm 1.17$ & $37.71 \pm 5.53^{\mathrm{a}}$ & $123.48 \pm 24.00^{\mathrm{b}, \mathrm{c}}$ & $30.56 \pm 3.69^{\mathrm{a}}$ \\
$\mathrm{t}_{1 / 2}, \mathrm{~h}$ & $3.01 \pm 0.60$ & $6.34 \pm 1.13^{\mathrm{a}}$ & $17.53 \pm 6.11^{\mathrm{b}, \mathrm{c}}$ & $3.82 \pm 0.92$ \\
$\mathrm{~T}_{\max }, \mathrm{h}$ & $0.46 \pm 0.29$ & $0.67 \pm 0.26$ & $1.25 \pm 0.27^{\mathrm{b}}$ & $1.17 \pm 0.26^{\mathrm{a}}$ \\
$\mathrm{CL}, \mathrm{l} / \mathrm{h} / \mathrm{kg}$ & $0.55 \pm 0.04$ & $0.27 \pm 0.04^{\mathrm{a}}$ & $0.08 \pm 0.02^{\mathrm{b}, \mathrm{c}}$ & $0.33 \pm 0.04^{\mathrm{a}}$ \\
$\mathrm{C}_{\max }, \mathrm{mg} / \mathrm{l}$ & $4.15 \pm 0.39$ & $4.38 \pm 0.75$ & $6.52 \pm 0.60^{\mathrm{b}, \mathrm{c}}$ & $5.54 \pm 0.32^{\mathrm{a}}$
\end{tabular}

${ }^{\mathrm{a}} \mathrm{P}<0.05$ vs. control. ${ }^{\mathrm{b}} \mathrm{P}<0.05$ vs. prasugrel alone group $(\mathrm{n}=6)$. ${ }^{\mathrm{c}} \mathrm{P}<0.05$ vs. simvastatin alone group ( $\mathrm{n}=6$ ). Ctl, control; Pra, prasugrel; Sim, simvastatin; AUC, area under the concentration/time curve; CL, clearance; $\mathrm{C}$, concentration; $\mathrm{T}$, time.
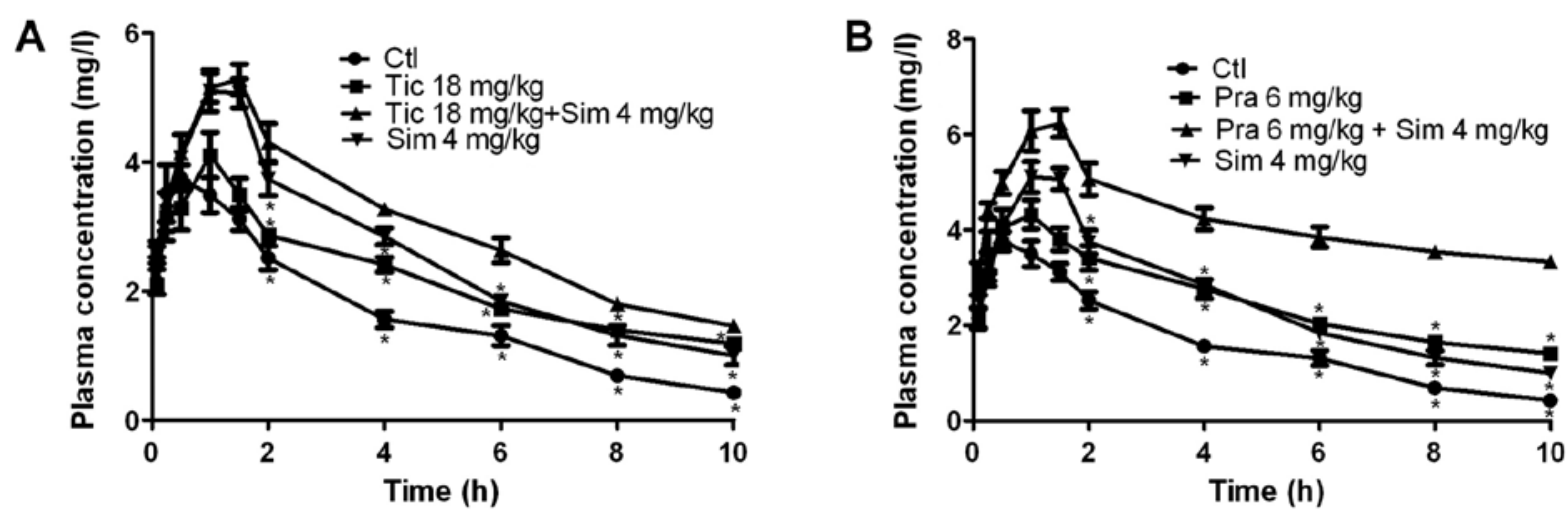

Figure 5. Plasma concentration vs. time curve of dapsone. (A) Control, ticagrelor, co-administration with simvastatin and simvastatin alone groups (mean \pm SD). (B) Control, prasugrel, co-administration with simvastatin and simvastatin alone groups (mean $\pm \mathrm{SD}$ ). " $\mathrm{P}<0.05$ vs. control ( $\mathrm{n}=6$ ). $\mathrm{Ctl}$, control; Tic, ticagrelor; Sim, simvastatin; Pra, prasugrel.

activity and subsequently increase the plasma concentration of ticagrelor, which results in adverse effects such as bleeding. However, prasugrel is a prodrug, and combination with statins could inhibit the metabolism of prasugrel and reduce its therapeutic effect. As an inhibitor of CYP3A4, ticagrelor will slow down the metabolism of simvastatin and increase its plasma concentration. As stated in the literature (32), ticagrelor significantly increases the potency of CYP3A4-metabolized statins, and it has been confirmed that the efficacy of the statins is highly increased when administered in combination with ticagrelor (14). Therefore, the present study aimed to explore its mechanism of the increased efficacy of statins in the combination with ticagrelor or prasugrel. The mechanism was revealed by detecting the activity, protein and mRNA expression of CYP3A4 in rat model and liver microsome, and pharmacokinetic parameters of the probe drug dapsone in rats.

To explore the underlying mechanism of the effects of ticagrelor or prasugrel on the activity of CYP3A4, the protein 
expression of CYP3A4 was examined. The results demonstrated that ticagrelor or prasugrel could inhibit the protein expression of CYP3A4. This result was consistent with the finding that they could inhibit the activity of CYP3A4 in vitro. To clarify whether the alteration in CYP3A4 protein expression was due to changes in transcript levels, the mRNA level of CYP3A4 was detected. Notably, the mRNA level of CYP3A4 was increased following treatment with prasugrel or ticagrelor alone. It has previously been reported that the upregulation of CYP3A4 mRNA may be associated with the pregnane $X$ receptor (33). The inconsistency between the expression of mRNA and protein led to the evaluation of whether ticagrelor or prasugrel could accelerate the degradation of the CYP3A4 protein. CYP3A4 has been observed to be degraded via the proteasomal pathway (34). Therefore, the present study used MG132, a proteasome inhibitor, to investigate the degradation of CYP3A4. It was observed that the decreased protein level of CYP3A4 induced by ticagrelor or prasugrel was reversed following treatment with MG132. Taken together, these results demonstrated that ticagrelor- and prasugrel-induced CYP3A4 protein degradation was mediated by the proteasomal pathway. The same results were also observed when ticagrelor or prasugrel were administered concurrently with statins.

In addition, the pharmacokinetic parameters of the probe drug dapsone were detected in vivo following the concurrent administration of ticagrelor or prasugrel with simvastatin. Compared with ticagrelor or prasugrel alone, $\mathrm{AUC}_{(0-\mathrm{t})}, \mathrm{AUC}_{(0-\infty)}$ and $\mathrm{t}_{1 / 2}$ values were increased and CL was decreased following the combination of ticagrelor or prasugrel with simvastatin. These results revealed that the co-administration of ticagrelor or prasugrel with statins had a stronger inhibitory effect against CYP3A4, when compared with ticagrelor or prasugrel alone. DDI was detected following the combined use of P2Y12 inhibitors and statins, however, no bleeding was observed in the internal organs or skin of the rats. According to a previous report, simvastatin can reduce potassium voltage-gated channel subfamily $\mathrm{H}$ member 2 current by accelerating channel inactivation, and can increase the risk of long QT syndrome (LQTS) with long-term use (35). The combination of ticagrelor with simvastatin may lead to an increase in the plasma concentration of simvastatin by inhibiting CYP3A4 activity, which may in turn contribute to the higher risk of drug induced LQTS and torsade de pointes. Based on the fact that simvastatin can induce cardiotoxicity, caution should be exercised when combining it with other drugs that are metabolized by CYP3A4 to avoid greater cardiotoxicity, especially LQTS. Although future experimental studies should be conducted with humans due to interspecies differences, the results of the present study provide some useful information about the rational clinical use of ticagrelor, prasugrel and statins.

The present study demonstrated that both ticagrelor and prasugrel could inhibit the activity of CYP3A4. The inhibitory effect of prasugrel was stronger than that of ticagrelor. Co-administration of ticagrelor or prasugrel with statins showed enhanced inhibitory effects on CYP3A4 activity both in vitro and in vivo. Additional experiments confirmed that the mechanism underlying the effect of the two investigated P2Y12 inhibitors on the activity of CYP3A4 involved the reduction of the protein level of CYP3A4 by promoting protein degradation through the proteasomal pathway, and that the same mechanism applied when the drugs were used in combination with statins.

When prasugrel and ticagrelor are combined with statins such as simvastatin, the inhibition of cytochrome is stronger than that observed with a single drug, and metabolic DDIs do exist between them. Therefore, when P2Y12 inhibitors and statins are used in combination, particular attention should be paid to adjusting their doses in order to avoid unexpected DDIs and the possible risk of statin- or P2Y12 inhibitor-related adverse reactions.

\section{Acknowledgements}

Not applicable.

\section{Funding}

This study was supported by grants from the National Natural Science Foundation of China (grant no. 81673636).

\section{Availability of data and materials}

The datasets used and/or analyzed during the current study are available from the corresponding author on reasonable request.

\section{Authors' contributions}

BZ conceived and designed the experiments, performed the experiments, analyzed the data, wrote the paper, and prepared figures and tables. GeZ, QF, FW, YL, YZ, LZ, and GuZ performed the experiments. BL made important contributions to the conception and design of the study, contributed reagents/materials/analysis tools and revised the manuscript critically for important intellectual content. All the authors reviewed drafts of the paper.

\section{Ethics approval and consent to participate}

The animal experiments were conducted in accordance with the guidelines of the Ethics Committee of Harbin Medical University.

\section{Patient consent for publication}

Not applicable.

\section{Competing interests}

The authors declare that they have no competing interests.

\section{References}

1. Chen JJ, Zhang JX, Zhang XQ, Qi MJ, Shi MZ, Yang J, Zhang KZ, Guo C and Han YL: Effects of diosmetin on nine cytochrome P450 isoforms, UGTs and three drug transporters in vitro. Toxicol Appl Pharmacol 334: 1-7, 2017.

2. Tang S, Chen A, Zhou X, Zeng L, Liu M and Wang X: Assessment of the inhibition risk of shikonin on cytochrome P450 via cocktail inhibition assay. Toxicol Lett 281: 74-83, 2017. 
3. Lin JH: CYP induction-mediated drug interactions: In vitro assessment and clinical implications. Pharm Res 23: 1089-1116, 2006.

4. Lu J, Shao Y, Qin X, Liu D, Chen A, Li D, Liu M and Wang X: CRISPR knockout rat cytochrome P450 3A1/2 model for advancing drug metabolism and pharmacokinetics research. Sci Rep 7: 42922, 2017.

5. Xie B, Lu YY, Luo ZH, Qu Z, Zheng CG, Huang XA, Zhou HY, $\mathrm{Hu}$ YJ and Shen XL: Tenacigenin B ester derivatives from Marsdenia tenacissima actively inhibited CYP3A4 and enhanced in vivo antitumor activity of paclitaxel. J Ethnopharmacol 235 309-319, 2019

6. Rendic S and Guengerich FP: Survey of human oxidoreductases and cytochrome P450 enzymes involved in the metabolism of xenobiotic and natural chemicals. Chem Res Toxicol 28: 38-42, 2015.

7. Wanwimolruk S and Prachayasittikul V: Cytochrome P450 enzyme mediated herbal drug interactions (Part 1). EXCLI J 13: 347-391, 2014.

8. Jin $\mathrm{C}$, Kim $\mathrm{MH}$, Bang $\mathrm{J}$ and Serebruany V: A prospective, randomized, open-label, blinded, endpoint study exploring platelet response to half-dose prasugrel and ticagrelor in patients with the acute coronary syndrome: HOPE-TAILOR study. Cardiology 138: 201-206, 2017.

9. Vyas A, Bash LD, Patel MD and Simpson RJ Jr: Changes in treatment patterns and incremental health care utilization due to P2Y12-associated complications in patients with acute coronary syndrome. J Manag Care Spec Pharm 23: 947-956, 2017.

10. Amsterdam EA, Wenger NK, Brindis RG, Casey DE Jr, Ganiats TG, Holmes DR Jr, Jaffe AS, Jneid H, Kelly RF, Kontos MC, et al: 2014 AHA/ACC guideline for the management of patients with non-ST-elevation acute coronary syndromes: Executive summary: A report of the american college of cardiology/american heart association task force on practice guidelines. Circulation 130: 2354-2394, 2014.

11. Hamm CW, Bassand JP, Agewall S, Bax J, Boersma E, Bueno H, Caso P, Dudek D, Gielen S, Huber K, et al: ESC Guidelines for the management of acute coronary syndromes in patients presenting without persistent ST-segment elevation: The Task Force for the management of acute coronary syndromes (ACS) in patients presenting without persistent ST-segment elevation of the European Society of Cardiology (ESC). Eur Heart J 32: 2999-3054, 2011

12. Task Force on the management of ST-segment elevation acute myocardial infarction of the European Society of Cardiology (ESC); Steg PG, James SK, Atar D, Badano LP, Blömstrom-Lundqvist C, Borger MA, Di Mario C, Dickstein K, Ducrocq G, et al: ESC Guidelines for the management of acute myocardial infarction in patients presenting with ST-segment elevation. Eur Heart J 33: 2569-2619, 2012.

13. Wallentin L, Becker RC, Budaj A, Cannon CP, Emanuelsson H, Held C, Horrow J, Husted S, James S, Katus H, et al: Ticagrelor versus clopidogrel in patients with acute coronary syndromes. N Engl J Med 361: 1045-1057, 2009.

14. Teng R, Mitchell PD and Butler KA: Pharmacokinetic interaction studies of co-administration of ticagrelor and atorvastatin or simvastatin in healthy volunteers. Eur J Clin Pharmacol 69: 477-487, 2013

15. Zhou D, Andersson TB and Grimm SW: In vitro evaluation of potential drug-drug interactions with ticagrelor: Cytochrome P450 reaction phenotyping, inhibition, induction, and differential kinetics. Drug Metab Dispos 39: 703-710, 2011.

16. Ancrenaz V, Deglon J, Samer C, Staub C, Dayer P, Daali Y and Desmeules J: Pharmacokinetic interaction between prasugrel and ritonavir in healthy volunteers. Basic Clin Pharmacol Toxicol 112: 132-137, 2013

17. Ramasamy S, Kiew LV and Chung LY: Inhibition of human cytochrome P450 enzymes by Bacopa monnieri standardized extract and constituents. Molecules 19:2588-2601, 2014

18. Umemura $\mathrm{K}$ and Iwaki $\mathrm{T}$ : The pharmacokinetics and pharmacodynamics of prasugrel and clopidogrel in healthy Japanese volunteers. Clin Pharmacol Drug Dev 5: 480-487, 2016.
19. Teng R, Hammarberg M, Carlson GF, Bokelund-Singh S, Ruderfelt $\mathrm{T}$ and Blychert E: Pharmacokinetic profiles of ticagrelor orodispersible tablets in healthy western and Japanese Subjects. Clin Drug Investig 37: 1035-1045, 2017.

20. Livak KJ and Schmittgen TD: Analysis of relative gene expression data using real-time quantitative PCR and the 2(-Delta Delta $\mathrm{C}(\mathrm{T})$ ) method. Methods 25: 402-408, 2001

21. Savarese $\mathrm{G}$ and Lund LH: Ticagrelor versus prasugrel in patients with acute coronary syndrome undergoing percutaneous coronary intervention: An unresolved issue. Int J Cardiol 249: 77-78, 2017.

22. Lodola A: Developing combination drugs in preclinical studies. Methods Mol Biol 691: 3-16, 2011

23. Zhi D, Feng PF, Sun JL, Guo F, Zhang R, Zhao X and Li BX: The enhancement of cardiac toxicity by concomitant administration of Berberine and macrolides. Eur J Pharm Sci 76: 149-155, 2015.

24. Farid NA, Small DS, Payne CD, Jakubowski JA, Brandt JT, Li YG, Ernest CS, Salazar DE, Konkoy CS and Winters KJ: Effect of atorvastatin on the pharmacokinetics and pharmacodynamics of prasugrel and clopidogrel in healthy subjects. Pharmacotherapy 28: 1483-1494, 2008.

25. Zhou S, Yung Chan S, Cher Goh B, Chan E, Duan W, Huang M and McLeod HL: Mechanism-based inhibition of cytochrome P450 3A4 by therapeutic drugs. Clin Pharmacokinet 44: 279-304, 2005.

26. Lehmann JM, McKee DD, Watson MA, Willson TM, Moore JT and Kliewer SA: The human orphan nuclear receptor PXR is activated by compounds that regulate CYP3A4 gene expression and cause drug interactions. J Clin Invest 102: 1016-1023, 1998.

27. Ojeifo O, Wiviott SD, Antman EM, Murphy SA, Udell JA, Bates ER, Mega JL, Sabatine MS and O'Donoghue ML: Concomitant administration of clopidogrel with statins or calcium-channel blockers: Insights from the TRITON-TIMI 38 (trial to assess improvement in therapeutic outcomes by optimizing platelet inhibition with prasugrel-thrombolysis in myocardial infarction 38). JACC Cardiovasc Interv 6: 1275-1281, 2013.

28. Holmberg MT, Tornio A, Hyvarinen H, Neuvonen M, Neuvonen PJ, Backman JT and Niemi M: Effect of grapefruit juice on the bioactivation of prasugrel. Br J Clin Pharmacol 80: 139-145, 2015.

29. Wang ZY, Chen M, Zhu LL, Yu LS, Zeng S, Xiang MX and Zhou Q: Pharmacokinetic drug interactions with clopidogrel: updated review and risk management in combination therapy. Ther Clin Risk Manag 11: 449-467, 2015.

30. Ju A, Li YY, Qu Z and Li Q: Impact of the herbal breviscapine on the pharmacokinetics of simvastatin in rats: The involvement of CYP3A4. Drug Res (Stuttg) 67: 271-274, 2017.

31. Shu N, Hu M, Ling Z, Liu P, Wang F, Xu P, Zhong Z, Sun B, Zhang M, Li F, et al: The enhanced atorvastatin hepatotoxicity in diabetic rats was partly attributed to the upregulated hepatic Cyp3a and SLCO1B1. Sci Rep 6: 33072, 2016.

32. Dinicolantonio JJ and Serebruany VL: Exploring the ticagrelor-statin interplay in the PLATO trial. Cardiology 124: 105-107, 2013.

33. Huan JY, Streicher JM, Bleyle LA and Koop DR: Proteasomedependent degradation of cytochromes P450 2E1 and 2B1 expressed in tetracycline-regulated HeLa cells. Toxicol Appl Pharmacol 199: 332-343, 2004.

34. Liao M, Faouzi S, Karyakin A and Correia MA: Endoplasmic reticulum-associated degradation of cytochrome P450 CYP3A4 in Saccharomyces cerevisiae: Further characterization of cellular participants and structural determinants. Mol Pharmacol 69: 1897-1904, 2006.

35. Feng PF, Zhao L, Guo F, Zhang B, Fang L, Zhan G, Xu X, Fang Q, Liang $\mathrm{Z}$ and $\mathrm{Li} \mathrm{B}$ : The enhancement of cardiotoxicity that results from inhibiton of CYP 3A4 activity and hERG channel by berberine in combination with statins. Chem Biol Interact 293 . $115-123,2018$. 